\title{
Learning and Memory and Synaptic Plasticity Are Impaired in a Mouse Model of Rett Syndrome
}

\author{
Paolo Moretti, ${ }^{1,2}$ Jonathan M. Levenson, ${ }^{3}$ Fortunato Battaglia, ${ }^{7}$ Richard Atkinson, ${ }^{1}$ Ryan Teague, ${ }^{1}$ Barbara Antalffy, ${ }^{4}$ \\ Dawna Armstrong, ${ }^{4}$ Ottavio Arancio, ${ }^{7}$ J. David Sweatt, ${ }^{3}$ and Huda Y. Zoghbi ${ }^{1,2,3,5,6}$ \\ Departments of ${ }^{1}$ Molecular and Human Genetics, ${ }^{2}$ Neurology, ${ }^{3}$ Neuroscience, ${ }^{4}$ Pathology, and ${ }^{5}$ Pediatrics, and ${ }^{6}$ Howard Hughes Medical Institute, Baylor \\ College of Medicine, Houston, Texas 77030, and ${ }^{7}$ Center for Dementia Research, Nathan S. Kline Institute for Psychiatric Research-New York University, \\ Orangeburg, New York 10962
}

Loss-of-function mutations or abnormal expression of the X-linked gene encoding methyl CpG binding protein 2 (MeCP2) cause a spectrum of postnatal neurodevelopmental disorders including Rett syndrome (RTT), nonsyndromic mental retardation, learning disability, and autism. Mice expressing a truncated allele of $\operatorname{Mecp2}\left(\operatorname{Mecp}^{308}\right)$ reproduce the motor and social behavior abnormalities of RTT; however, it is not known whether learning deficits are present in these animals. We investigated learning and memory, neuronal morphology, and synaptic function in $M e c p 2^{308}$ mice. Hippocampus-dependent spatial memory, contextual fear memory, and social memory were significantly impaired in $\operatorname{Mec} p 2^{308}$ mutant males $\left(\operatorname{Mec} p 2^{308 / Y}\right)$. The morphology of dendritic arborizations, the biochemical composition of synaptosomes and postsynaptic densities, and brain-derived neurotrophic factor expression were not altered in these mice. However, reduced postsynaptic density cross-sectional length was identified in asymmetric synapses of area CA1 of the hippocampus. In the hippocampus of symptomatic Mecp $2^{308 / Y}$ mice, Schaffer-collateral synapses exhibited enhanced basal synaptic transmission and decreased paired-pulse facilitation, suggesting that neurotransmitter release was enhanced. Schaffer-collateral long-term potentiation (LTP) was impaired. LTP was also reduced in the motor and sensory regions of the neocortex. Finally, very early symptomatic $M e c p 2^{308 / Y}$ mice had increased basal synaptic transmission and deficits in the induction of long-term depression. These data demonstrate a requirement for $\mathrm{MeCP} 2$ in learning and memory and suggest that functional and ultrastructural synaptic dysfunction is an early event in the pathogenesis of RTT.

Key words: Rett syndrome; neurodevelopmental disorders; autism; synaptic plasticity; LTP; LTD; epigenetics; MeCP2; learning and memory

\section{Introduction}

Rett syndrome (RTT; MIM 312750) is an X-linked dominant disorder caused by loss-of-function mutations in the gene encoding methyl CpG binding protein 2 (MeCP2) (Amir et al., 1999). RTT is a frequent cause of mental retardation with autistic features in females. However, the spectrum of neurologic abnormalities associated with MeCP2 dysfunction extends beyond RTT, including nonsyndromic mental retardation in males and fe-

\footnotetext{
Received May 5, 2005; revised Sept. 14, 2005; accepted Nov. 10, 2005.

P.M. was supported by National Institutes of Health (NIH) Grants NS043969 and NS049181 and by the March of Dimes Basil O'Connor Starter Scholar Research Award. H.Y.Z. was supported by NIH Grant HD40301, funds from Cure Autism Now, and NIH Grant HD24064 to the Baylor College of Medicine Mental Retardation and Developmental Disabilities Research Center. O.A. was supported by NIH Grant NS049442. J.D.S. and J.M.L. were supported by NIH Grants MH57014 and NS13546. H.Y.Z. is an investigator with the Howard Hughes Medical Institute. We thank members of the Zoghbi laboratory for feedback provided during the course of this study and $0^{\prime} B$ Brian Smith for his assistance with statistical analysis. We are grateful to Jeff Neul, Aaron Bowman, Bryan McGill, and John Fryer for their critical reading of this manuscript.

Correspondence should be addressed to Huda Y. Zoghbi, Baylor College of Medicine, Mail Stop 225, One Baylor Plaza, Houston, TX 77030. E-mail: hzoghbi@bcm.tmc.edu.

F. Battaglia's present address: Department of Physiology and Pharmacology, The City University of New York Medical School, New York, NY 10031.

0 . Arancio's present address: Department of Pathology, Columbia University, New York, NY 10032.

D01:10.1523/JNEUROSCI.2623-05.2006

Copyright $\odot 2006$ Society for Neuroscience $\quad$ 0270-6474/06/260319-09\$15.00/0
}

males (Percy, 2002), mild learning disability in females with favorable X-chromosome inactivation (Wan et al., 1999; Amir et al., 2000), and autism (Lam et al., 2000; Beyer et al., 2002; Carney et al., 2003). Thus, understanding the role of MeCP2 in normal and pathologic brain function may shed light not only on RTT but also other postnatal neurodevelopmental disorders.

RTT girls generally appear to achieve normal developmental milestones until 6-18 months of age, when they enter a period of regression with loss of acquired cognitive, social, and motor skills (Hagberg et al., 1983). The exact nature of the cognitive deficits that afflict RTT patients is unknown, partly as a result of the motor impairments, which make intelligence testing a significant challenge. Yet, cognitive impairments are present in humans with MECP2 mutations. Even females with favorable skewing of X inactivation and predominant expression of the wild-type (wt) MECP2 allele have learning disability (Schanen and Francke, 1998; Wan et al., 1999). Defining the exact nature of cognitive abnormalities associated with MeCP2 dysfunction is an important challenge.

Several observations suggest that the axonodendritic connections may be affected by the disease and that MECP2 mutations may disrupt formation, maturation, and/or pruning of synapses. Selective reduction of dendritic arborizations has been described 
in pyramidal neurons of layers III and V of the frontal, motor, and inferior temporal regions and layer IV of the subiculum (Armstrong et al., 1995). Dendritic spine loss was observed in the frontal cortex (Belichenko and Dahlstrom, 1995), and decreased synaptophysin staining was reported in speech areas (Belichenko et al., 1997). Transcriptional profiling of mRNA from the cortex of RTT girls revealed expression abnormalities of synaptic markers (Colantuoni et al., 2001). Last, in vitro studies suggested that transcription of the gene encoding brain-derived neurotrophic factor (BDNF) is regulated by MeCP2 in a neuronal activitydependent manner (Chen et al., 2003; Martinowich et al., 2003).

The ability to model some aspects of the cognitive impairments of RTT in the mouse would provide an important stepping stone in our understanding of this disease. Truncating mutations of MECP2 are a frequent cause of RTT, and we have shown that mice expressing a truncated allele of Mecp2 (Mecp $\left.2^{308}\right)$ have motor dysfunction and social interaction deficits (Shahbazian et al., 2002; Moretti et al., 2005), phenotypes reminiscent of key manifestations of the disease. The phenotypes are more variable in females than males because of unbalanced patterns of $\mathrm{X}$-chromosome inactivation generally favoring expression of the wild-type allele (Young and Zoghbi, 2004). We hypothesized that $\mathrm{MeCP} 2$ dysfunction may cause functional and/or structural neuronal abnormalities resulting in the complex neurologic deficits of RTT and related disorders. To test this hypothesis, we studied learning and memory, neuronal morphology, and synaptic plasticity in $M e c p 2^{308}$ mice.

\section{Materials and Methods}

\section{Behavioral testing}

Test animals. The experimental subjects used in all experiments were pure $129 / \mathrm{SvEv}$ wild-type and $M e c p 2^{308 / Y}$ littermates that were bred in our animal facility from crosses of heterozygous Mecp $2^{308 / \mathrm{X}}$ mutant females with wild-type males. All testing was done by observers blind to the genotype of the subjects. Separate groups of mice were used for each behavioral experiment, electrophysiology, biochemistry, and microscopy.

Morris water task. Mice ( $\left.n=14 \mathrm{wt} ; n=16 \mathrm{Mecp} 2^{308 / \mathrm{Y}}\right)$ were trained to find a hidden platform in a circular pool ( $1.38 \mathrm{~m}$ diameter) of water. Each mouse was given four training trials per day for eight consecutive days. Mice were started in different quadrants on a random basis during each day of training and all four quadrants were used on any given day. The maximum swimming time allowed on each trial was $60 \mathrm{~s}$, and the intertrial interval was $60 \mathrm{~s}$ ( $30 \mathrm{~s}$ on the platform and $30 \mathrm{~s}$ off the platform). The time for the mouse to locate the platform was recorded (escape latency and distance traveled). After the last trial, the probe trial was conducted: the platform was removed, and the time spent searching each quadrant (quadrant search time) was recorded. After completion of the probe test, a visible platform trial was administered, starting the mice from a different quadrant than the one used for the probe test and allowing a maximum of $60 \mathrm{~s}$ to reach the platform. A separate visible platform trial was also administered to a group of naive mice allowing a maximum of $60 \mathrm{~s}$ to reach the platform. Escape latency and distance traveled data obtained during training were analyzed using a two-way (genotype $\times$ trial block) ANOVA with repeated measures. Search data from the probe trial were analyzed by individual one-way ANOVA and $t$ test for post hoc comparisons. A one-way ANOVA was used to compare the search time data for the training quadrant between wild-type and mutant mice.

Contextual fear conditioning test. The experiments were conducted in a test chamber with a grid floor that could deliver an electric shock (Med Associates/Actimetrics chamber system; Med Associates, Georgia, VT). Each mouse ( $n=28$ per genotype) was initially placed into the chamber and left undisturbed for 2 min after which a single $(2 \mathrm{~s}, 0.5 \mathrm{~mA})$ foot shock, which served as the unconditioned stimulus, was applied. After an additional $30 \mathrm{~s}$, the mouse was removed and returned to its home cage. Responses such as running, jumping, and vocalizing in response to the shock were recorded. After an interval of $24 \mathrm{~h}$, each mouse was returned to the test chamber and freezing behavior was recorded for 5 min (context test). Freezing behavior was recorded automatically by the instrument. The number of freezing intervals was converted to a percentage freezing value. The data were analyzed using a one-way ANOVA.

Social recognition test. Adult mice ( $n=15$ per genotype) were placed into individual cages $(28.5 \times 17.5 \times 12 \mathrm{~cm})$ immediately before the experimental session and allowed to habituate to the new environment for $15 \mathrm{~min}$. A juvenile male (pure C57BL/6J wild-type, 3-4 weeks of age) was placed into the cage with each adult mouse for a total of $2 \mathrm{~min}$. The social investigation of the juvenile by the adult mouse was observed by a trained observer who timed the duration of the investigation with a hand-held stopwatch. Behaviors that were scored as social investigation included the following: direct contact, sniffing, and close following (within $<1 \mathrm{~cm}$ ). There were no aggressive encounters between animals. Naive mice were used in all encounters. Each wild-type and $M e c p 2^{308 / Y}$ mouse was exposed to the same juvenile mouse after a $24 \mathrm{~h}$ delay. The social investigation of the juvenile was scored as above. Data were analyzed using a two-way ANOVA (genotype $\times$ time) with repeated measures, using genotype as a between-subject factor and time as a withinsubject factor. The $t$ test was used for post hoc analysis.

Histology, immunoblotting, and transmission electron microscopy Golgi staining and Sholl analysis. Six pairs of wild-type and Mecp $2^{308 / Y}$ mice between 12 and 15 months of age and three pairs of wild-type/ mutant mice at 6 weeks of age were used for these studies. Whole brains were removed after cervical dislocation and quickly washed in PBS. Golgi staining was performed using FD Rapid Golgi Stain (FD Neuro Technologies, Ellicott City, MD) according to the instructions of the manufacturer. Sagittal brain sections were cut at $50 \mu \mathrm{m}$ thickness. Sections from the best three pairs of brains were used to make camera lucida drawings of the pyramidal neurons of layers three and five in the frontal cortex. Ten neurons were drawn from each layer and each mouse for a total of 30 neurons per genotype. The apical and basilar dendrites of each pyramidal neuron were subjected to a Sholl analysis. A set of concentric circles each $20 \mathrm{~mm}$ apart was superimposed on camera lucida drawings of each neuron starting from the center of the cell body. The number of dendrites that intercepted each circle was counted, extending the analysis to 300 $\mathrm{mm}$ from the cell soma. Data were analyzed using a two-way ANOVA (genotype $X$ distance from cell body center) with repeated measures, using genotype and subject as a between-subject factor and distance as a within-subject factor.

Preparation of synaptosomes and postsynaptic densities. Whole brains were removed from mice after cervical dislocation and washed in ice-cold PBS. The olfactory bulbs, cerebellum, and brainstem were dissected and discarded, and the remaining tissue was cut into small fragments and homogenized with Dounce homogenizers in $320 \mathrm{~mm}$ sucrose, $4 \mathrm{~mm}$ HEPES-NaOH, pH 7.3, with $5 \times$ protease inhibitor cocktail (Roche Molecular Biochemicals, Hertforshire, $\mathrm{UK}$ ), $\mathrm{NaF}$, and $\mathrm{Na}$ orthovanadate (4 $\mathrm{ml}$ of buffer per brain). The homogenate was centrifuged twice at $1000 \times$ $g$ for $5 \mathrm{~min}$ at $4^{\circ} \mathrm{C}$, and the supernatant was then centrifuged at $9000 \times g$ for $15 \mathrm{~min}$ at $4^{\circ} \mathrm{C}$. The resulting pellet was resuspended in homogenization buffer (see above) and centrifuged again at $9500 \times g$ for $15 \mathrm{~min}$ at $4^{\circ} \mathrm{C}$. The pellet resuspended in homogenization buffer contained synaptosomes that were used for protein expression analysis (see below). To obtain postsynaptic densities (PSDs), the synaptosome fraction was incubated in $0.5 \%$ Triton X-100 for $15 \mathrm{~min}$ at $4^{\circ} \mathrm{C}$, centrifuged at $9500 \times \mathrm{g}$ for $15 \mathrm{~min}$ at $4^{\circ} \mathrm{C}$, and the supernatant was centrifuged at $32,000 \times g$ for $20 \mathrm{~min}$ at $4^{\circ} \mathrm{C}$. The resulting pellet containing PSDs was resuspended in $40 \mathrm{~mm}$ Tris- $\mathrm{HCl}, \mathrm{pH} \mathrm{8.0,} \mathrm{and} \mathrm{used} \mathrm{for} \mathrm{additional} \mathrm{analysis.}$

Western blot analysis. Total protein levels were quantified using a modified Bradford assay (Bio-Rad Protein Assay, Bio-Rad, Hercules, CA), and $5 \mu \mathrm{g}$ of protein was loaded onto a $4-15 \%$ gradient SDSpolyacrylamide gel and separated by electrophoresis. Proteins were transferred from the gel to a nitrocellulose membrane (Schleicher \& Schuell, Dassel, Germany). Blots were blocked in 5\% blotting grade blocker nonfat dry milk (Bio-Rad) in Tris-buffered saline with $0.1 \%$ Tween 20 (TBS-T) for $1 \mathrm{~h}$. Membranes were then incubated with primary antibody diluted in blocking solution for $2 \mathrm{~h}$ at room temperature. The 
membranes were washed three times for 5 min with TBS-T and then incubated with blocking solution containing horseradish peroxidaseconjugated secondary antibody for $1 \mathrm{~h}$. Excess antibody was washed off with three 5 min TBS-T washes, and the antibody conjugates were visualized by enhanced chemiluminescence (Amersham Biosciences, Arlington Heights, IL). A minimum of three samples per genotype was tested with each antibody.

Antibodies. Most antibodies used in this study were obtained from commercial sources (supplemental Table 1, available at www.jneurosci.org as supplemental material). Alternatively spliced isoforms of the NMDA receptor subunit 1 were detected using anti-C2 and C2' antibodies (kindly provided by Dr. Michael Ehlers, Duke University Medical Center, Durham, NC).

Transmission electron microscopy. Seven 6-week-old mice (four wildtype and three mutant) were anesthetized with $20 \mathrm{mg}$ of Avertin and perfused at $1 \mathrm{ml} / \mathrm{min}$ for $15 \mathrm{~min}$ transcardially with a fixative consisting of $1 \%$ glutaraldehyde, $1 \%$ paraformaldehyde, and $2 \mathrm{mM} \mathrm{CaCl}_{2}$ in $0.1 \mathrm{M}$ cacodylate buffer, $\mathrm{pH}$ 7.4. Mouse brains were removed and immediately submerged in fixative while the hippocampus was removed and trimmed limiting the tissue to the CA1 region, which was subdivided into four to six tissue blocks. After $1 \mathrm{~h}$ at room temperature, tissue blocks were stored in fixative overnight at $4^{\circ} \mathrm{C}$. Tissue was washed, postfixed in $2 \% \mathrm{OsO} 4$ and $0.1 \mathrm{M}$ cacodylate buffer, $\mathrm{pH} 7.4$, and rewashed in $\mathrm{H}_{2} \mathrm{O}$. Blocks were stained en block with $1 \%$ uranyl acetate for $30 \mathrm{~min}$, washed in $\mathrm{H}_{2} \mathrm{O}$, and dehydrated through a graded alcohol series followed by propylene oxide and embedded in Scipoxy Resin (EBS Sciences, East Granby, CT). Blocks were trimmed to include pyramidal cell dendritic tips and 60-70 nm sections were cut, mounted on bare nickel grids, and stained with $1 \%$ uranyl acetate and $0.2 \%$ lead citrate. For each sample, 10 montage images consisting of 12 adjacent $2 \mathrm{~K}$ pixel $\times 2 \mathrm{~K}$ pixel regions at $10,000 \times$ were collected using a Jeol (Peabody, MA) 1010 TEM with a Gatan (Pleasanton, CA) Ultrascan 1000 camera and used to produce a $7.8 \times 5.8 \mu \mathrm{m}$ composite image with Gatan Digital Micrograph software. Where possible, all images collected for each composite followed the margin of a single dendritic membrane. From these images, the number of asymmetric PSDs ( $n>50$ per genotype), the cross-sectional length of the PSD ( $n>240$ per genotype), the number of synaptic vesicles judged to be in contact with the presynaptic membrane spanning the length of the PSD ( $n>240$ per genotype), and the number of synaptic vesicles clustered in the vicinity but not in contact with the presynaptic membrane directly across from the PSD ( $n>240$ per genotype) were tabulated using NIH Image J software. Counts of vesicle number were square root transformed to approximate normal distribution. PSD length measurements were normalized using a logarithmic transformation. The median of each measurement per mouse was used to compare wild-type and mutant samples using a Mann-Whitney $U$ test.

\section{Electrophysiology}

Hippocampus slice preparation. Animals were killed by cervical dislocation, followed by decapitation. The brain was immersed in ice-cold cutting saline (CS) (in mm: 110 sucrose, $60 \mathrm{NaCl}, 3 \mathrm{KCl}, 1.25 \mathrm{NaH}_{2} \mathrm{PO}_{4}, 28$ $\mathrm{NaHCO}_{3}, 0.5 \mathrm{CaCl}_{2}, 7 \mathrm{MgCl}_{2}, 5$ glucose, 0.6 ascorbate) before isolation of the caudal portion containing the hippocampus and entorhinal cortex. Transverse slices $(400 \mu \mathrm{m})$ were prepared with a vibratome (Vibratome Company, St. Louis, MO). During isolation, slices were stored in ice-cold CS. After isolation, cortical tissue was removed and hippocampal slices were equilibrated in a mixture of $50 \% \mathrm{CS}$ and $50 \%$ artificial CSF (ACSF) (in mu: $125 \mathrm{NaCl}, 2.5 \mathrm{KCl}, 1.25 \mathrm{NaH}_{2} \mathrm{PO}_{4}, 25 \mathrm{NaHCO}_{3}, 2 \mathrm{CaCl}_{2}, 1$ $\mathrm{MgCl}_{2}, 25$ glucose) at room temperature for $30 \mathrm{~min}$ before transfer to the recording chamber.

Hippocampus slice electrophysiology. Electrophysiology was performed in an interface chamber (Fine Science Tools, Foster City, CA). Oxygenated ACSF $\left(95 \% / 5 \% \mathrm{O}_{2} / \mathrm{CO}_{2}, 30^{\circ} \mathrm{C}\right)$ was perfused into the recording chamber at a rate of $1 \mathrm{ml} / \mathrm{min}$. Electrophysiological traces were amplified with an AC-coupled amplifier (model 1800; A-M Systems, Carlsbourg, WA), digitized using a Digidata 1320A, and stored using Clampex software (Molecular Devices, Union City, CA). Extracellular stimuli were administered on the border of areas CA3 and CA1 along the Schaffer collaterals using a stimulus isolator (model 2200; A-M Systems) and
Teflon-coated, bipolar platinum electrodes (10-20 M $\Omega$ impedance). Field EPSPs (fEPSPs) were recorded in stratum radiatum with an ACSFfilled glass recording electrode (1-3 M $\Omega$ ). The relationship between the rising slope of the fiber volley and the rising slope of the fEPSP over various stimulus intensities ( $25 \mathrm{nA}$ to $1.5 \mu \mathrm{A}$ ) was used to assess baseline synaptic transmission. All subsequent experimental stimuli were set to an intensity that evoked an fEPSP that had a slope of $50 \%$ of the maximum fEPSP slope (100-700 nA). Paired-pulse facilitation (PPF) was investigated at various interstimulus intervals $(20,50,100,200$, and $300 \mathrm{~ms}$ ). Long-term potentiation (LTP) was induced by two different stimulation paradigms. Theta-burst LTP was induced by administering three trains of theta-burst stimulation. Each train consisted of 10 sets of bursts (four stimuli, $100 \mathrm{~Hz}$ ) with an interburst interval of $200 \mathrm{~ms}$. There was $20 \mathrm{~s}$ between each stimulus train. High-frequency stimulation LTP was induced by administering two $100 \mathrm{~Hz}$ tetani (1 s) with an intertetanus interval of $20 \mathrm{~s}$. Metabotropic glutamate receptor (mGluR)-dependent long-term depression (LTD) was induced by two different stimulus paradigms. The first paradigm consisted of exposing slices to (S)-3,5dihydroxyphenylglycine (DHPG; $50 \mu \mathrm{M}$ ) for $10 \mathrm{~min}$. Paired-pulse LTD was induced by administering 900 paired-pulse stimuli $(50 \mathrm{~ms}$ interstimulus interval) at $1 \mathrm{~Hz}$ in the presence of DL-2-amino-5phosphonopentanoic acid (AP-5; $50 \mu \mathrm{M}$ ) and a modified ACSF (same as above except for $5 \mathrm{~mm} \mathrm{KCl}$ and $10 \mathrm{~mm}$ glucose) (Huber et al., 2001). In all synaptic plasticity paradigms, synaptic efficacy was monitored $20 \mathrm{~min}$ before and $90 \mathrm{~min}$ after induction by recording fEPSPs every $20 \mathrm{~s}$ (traces were averaged for every $2 \mathrm{~min}$ interval). Slices that did not exhibit stable fEPSP slopes during the first $20 \mathrm{~min}$ of recording were excluded from the study. Input-output relationships were analyzed using a single exponential function $\left(Y=\right.$ Slope $\left._{\mathrm{MAX}} \times 1-e^{-K \times X}\right)$. Parameters used to fit input-output relationships were compared using an $F$ test. PPF, LTP, and LTD data were analyzed via two-way ANOVA with repeated measures. For analysis of LTP and LTD, data acquired before and after induction were analyzed separately. Post hoc comparisons after two-way ANOVA were made using the method of Bonferroni. Significance for all tests was set at $p<0.05$.

Cortical slice preparation. Coronal brain slices containing the region of the primary motor area M1 (forelimb representation) and primary sensory area S1 were prepared as described previously (Rioult-Pedotti et al., 1998). Briefly, slices of $400 \mu \mathrm{m}$ thickness were maintained in an interface chamber at $29^{\circ} \mathrm{C}$, in which they were superfused with ACSF of the following composition (in mM): $124.0 \mathrm{NaCl}, 4.4 \mathrm{KCl}, 1.0 \mathrm{Na}_{2} \mathrm{HPO}_{4}, 25.0$ $\mathrm{NaHCO}_{3}, 2.0 \mathrm{CaCl}_{2}, 2.0 \mathrm{MgSO}_{4}$, and 10 glucose, continuously bubbled with a $95 \% \mathrm{O}_{2}, 5 \% \mathrm{CO}_{2}$ mixture. Slices were permitted to recover for at least $180 \mathrm{~min}$ before recordings.

Cortical slice recordings. fEPSPs were recorded by placing lowresistance glass recording microelectrodes filled with saline solution (5 $\mathrm{M} \Omega$ resistance) in layer II/III, 200-350 $\mu \mathrm{m}$ below the pial surface in the M1 or S1 areas. For recording from M1 cortex, concentric bipolar platinum-iridium stimulation electrodes were placed horizontally in layer II/III ( $\sim 500 \mu \mathrm{m}$ from the recording electrode), whereas for recordings from S1 cortex, stimulation electrodes were placed vertically in layer IV. The average stimulation intensity inducing a minimal response was $\sim 4 \mathrm{~V}$. Basal synaptic transmission was assayed by plotting the stimulation intensity as a multiple of threshold intensity inducing a minimal response $(\sim 0.1 \mathrm{mV})$ against amplitude of extracellular EPSPs (fEPSPs) to generate input-output relationships. For LTP experiments, baseline stimulation was delivered every minute at an intensity that evoked a response $\sim 50 \%$ of the maximum evoked response. Baseline response was recorded for $15 \mathrm{~min}$ before beginning the experiment to assure stability of the response. M1-LTP was induced by applying the $\mathrm{GABA}_{\mathrm{A}}$ receptor antagonist bicuculline $(3.5 \mathrm{mM})$ within $100 \mu \mathrm{m}$ from the recording electrode using a glass pipette. The bicuculline pipette was retracted as soon as field potential responses to test stimulation increases to $\sim 150-200 \%$ of baseline. Immediately after bicuculline application, M1LTP was induced by applying a theta-burst stimulation (five pulses at 100 $\mathrm{Hz}$, with the bursts repeated at $5 \mathrm{~Hz}$ and each tetanus including six 10-burst trains separated by $10 \mathrm{~s}$ ) at double test intensity. For S1-LTP, the tetanus consisted of a theta burst stimulation (five pulses at $100 \mathrm{~Hz}$, with the bursts repeated at $5 \mathrm{~Hz}$ and each tetanus including three 10-burst 
trains separated by $10 \mathrm{~s}$ ). No bicuculline was applied to induce S1-LTP. Paired-pulse stimuli were not administered in our layer II/III cortical slice preparations, because they have not been previously characterized in the literature. Input-output curves were compared using a factorial ANOVA. LTP results acquired before and after induction were analyzed separately using a two-way ANOVA with repeated measures.

\section{Results}

Mecp $2^{308 / Y}$ mice have deficits of spatial memory in the Morris water maze

To determine whether learning and memory impairments are present in a mouse model of RTT, we used the hidden platform version of the Morris water maze. Mecp $2^{308 / Y}$ mice (20 weeks of age) were chosen for these experiments ( $n=14 \mathrm{wt}$; $n=16$ $M e c p 2^{308 / Y}$ ), because these animals display typical forelimb stereotypies and tremor but are otherwise not severely symptomatic. For instance, rotarod and balance beam performance are not significantly reduced at this age compared with wild-type littermates (P. Moretti and H. Y. Zoghbi, unpublished observation). Wild-type and mutant mice were able to reach a visible platform in $<1 \min \left(t_{(21)}=0.962 ; p>0.05\right)$, excluding the presence of sensory deficits that may prevent the animals from identifying visual cues. Furthermore, swimming speed was not reduced in mutant animals, excluding the presence of motor deficits that could confound the interpretation of the results (Fig. 1A). Although animals of both genotypes performed equally well in the first session and showed a progressive decrease in the time required to locate the hidden platform, Mecp $2^{308 / Y}$ mice took significantly longer than control littermates $\left(F_{(1,28)}=17.33 ; p<\right.$ 0.001 ) after the first day (Fig. $1 B$ ). There was also a significant interaction between genotype and day of training $\left(F_{(6.45,180.7)}=\right.$ $3.29 ; p<0.01)$, indicating that mutant mice learned the task at a different rate. A trend analysis confirmed this conclusion, demonstrating a significant linear $\left(F_{(1,28)}=7.05 ; p<0.05\right)$ and quadratic $\left(F_{(1,28)}=4.36 ; p<0.05\right)$ interaction between the group genotype and day of training. To control for the possibility that a ceiling effect on the first day of testing may influence the results, we also included in the analysis time on day 1 as a betweensubjects factor. There was no significant time $\times$ genotype $\times$ score on day 1 interaction $\left(F_{(7,182)}=1.77 ; p>0.05\right)$. However, the results remained highly significant for the interaction of genotype and time $\left(F_{(7,182)}=3.01 ; p<0.01\right)$. During the probe trial (Fig. $1 C)$, control mice spent significantly longer time in the quadrant in which the platform was previously located compared with the other quadrants, whereas Mecp $2^{308 / Y}$ mice spent similar amounts of time in all four sectors $\left(F_{(2.33,65.26)}=7.13 ; p=0.001\right.$ for the interaction of genotype and quadrant). Post hoc analysis showed significant genotype differences for the trained quadrant $\left(t_{(28)}=\right.$ $3.24 ; p<0.01)$. These data indicate that although wild-type animals displayed a spatially directed search strategy, mutant mice did not, indicating a deficit of learning and memory in a hippocampus-dependent spatial learning task.

Contextual fear conditioning is impaired in Mecp $2^{308 / Y}$ mice Subsequently, we used an additional learning and memory paradigm, contextual fear conditioning. First, we sought to determine whether 20-week-old wild-type and mutant mice responded similarly to foot shocks of varying intensity (up to $0.7 \mathrm{~mA}$ for $2 \mathrm{~s}$ ). There were no significant differences in the minimal current intensity required to elicit stereotyped behavioral responses (Fig. $1 D)$. Next, we used a training protocol consisting of a single foot shock of $0.5 \mathrm{~mA}$ for $2 \mathrm{~s}$ in a contextual fear conditioning cage. Testing the animals $24 \mathrm{~h}$ after training (Fig. $1 E$ ) showed a significant reduction in the amount of freezing in $M e c p 2^{308 / Y}$ mice
A

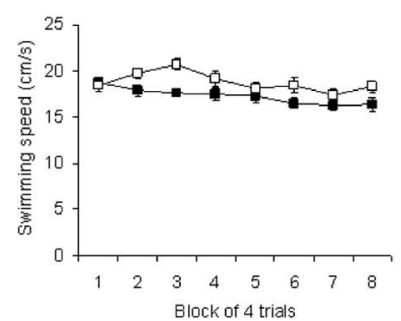

C
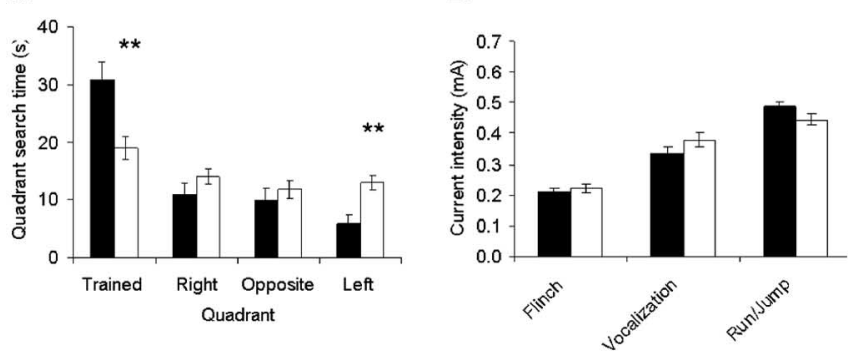

E

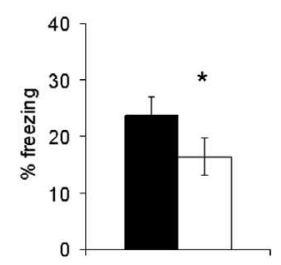

F

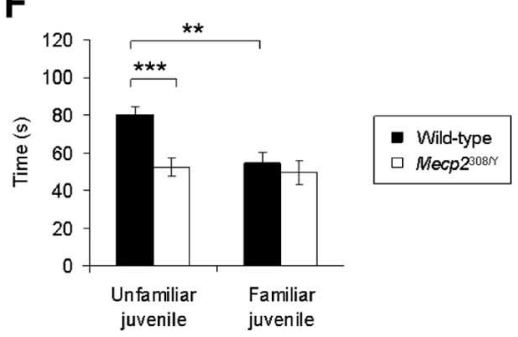

Figure 1. Mecp $2^{308 / \mathrm{V}}$ mice display learning and memory deficits. $A-C$, Abnormalities of spatial memory in the Morris water maze. $A, M e c p 2^{308 / Y}$ mice do not display reduced swimming speed compared with control littermates. $\boldsymbol{B}$, Mecp $2^{308 / Y}$ mice took significantly longer than control littermates in locating a submerged hidden platform $(p<0.001)$, and there was a significant interaction between genotype and day of training $(p<0.01)$. C, During the probe trial, whereas control mice spent significantly longer in the quadrant in which the platform was previously located, Mecp $2^{308 / Y}$ mice spent similar amounts of time in all four sectors ( $p=$ 0.001 for the interaction of genotype and quadrant). Post hoc analysis showed significant genotype differences for the trained quadrant $(p<0.01) . \boldsymbol{D}, \boldsymbol{E}$, Contextual fear conditioning is impaired in Mecp $2^{308 / Y}$ mice. $\boldsymbol{D}$, In control experiments, there were no significant differences in the threshold current required to elicit stereotyped behavioral responses in 20-week-old wildtype and mutant mice. E, Using a training protocol consisting of a single foot shock of $0.5 \mathrm{~mA}$ for 2 s in a contextual fear conditioning cage, $M e c p 2^{308 / V}$ mice showed a significant reduction in the amount of freezing compared with wild-type littermates $(p=0.023)$. $\boldsymbol{F}$, Deficits of hippocampus-dependent social recognition in Mecp $2^{308 / Y}$ mice. Naive Mecp $2^{308 / Y}$ mice spent less time than wild-type controls interacting with unfamiliar juvenile males $(p<0.001)$. Exposure to the same partners after a $24 \mathrm{~h}$ delay was associated with a significant reduction in interaction time in controls $(p<0.01)$ but not in mutant mice. Values represent mean \pm SEM. The asterisks indicate significant genotype differences $\left({ }^{*} p<0.05 ;{ }^{* *} p<0.01 ;{ }^{* * *} p<0.001\right)$. Error bars indicate SEM.

$\left(t_{(48.15)}=2.34 ; p=0.023 ; n=28\right.$ per group $)$. These results demonstrate that mice expressing a truncated Mecp 2 protein have learning and memory deficits in a task dependent on the function of the hippocampus and the amygdala.

Mecp $2^{308 / Y}$ mice show deficits of hippocampus-dependent longterm social memory

RTT is an autism spectrum disorder associated with loss of acquired motor, communication, and social skills. We have shown that $M e c p 2^{308 / Y}$ mice have social interaction impairments but intact social recognition in a working memory paradigm. To probe whether hippocampal dysfunction contributes to social interaction deficits, we used a long-term social memory test de- 
pendence on the function of the hippocampus. Wild-type and $M e c p 2^{308 / Y}$ mice showed significant differences in the interaction with juvenile males after repeated exposure on consecutive days $\left(F_{(1,27)}=11.07 ; p=0.003\right.$ for the interaction of genotype and time). As expected, naive Mecp $2^{308 / Y}$ mice spent less time than wild-type controls interacting with unfamiliar juvenile males $\left(t_{(27)}=4.13 ; p<0.001\right)$. Exposure to the same partner after a $24 \mathrm{~h}$ delay was associated with a reduction in interaction time in wildtype mice $\left(t_{(26)}=3.64 ; p=0.001\right)$. In contrast, Mecp $2^{308 / Y}$ mice spent similar amounts of time interacting with juveniles during both first and second exposures to them $\left(t_{(28)}=6.93 ; p=0.494\right)$ $($ Fig. $1 F)$. Repeated exposure of wild-type and $M e c p 2^{308 / Y}$ mice to the same juveniles over a $3 \mathrm{~d}$ period demonstrated a significant genotype $\times$ time interaction $\left(F_{(1,27)}=6.91 ; p<0.05\right)$. Wild-type mice demonstrated a significant decrease in the interaction time after a single exposure $\left(t_{(26)}=3.64 ; p=0.001\right)$ and after repeated exposures $\left(F_{(2,39)}=11.08 ; p<0.001\right)$. However, Mecp $2^{308 / Y}$ mice had no significant decrements of interaction time after either single $\left(t_{(28)}=0.69 ; p>0.05\right)$ or repeated $\left(F_{(2,42)}=2.77 ; p>0.05\right)$ exposures, indicating that simply increasing the number of interactions did not overcome the social recognition deficit. The result that even after additional exposures to the same juvenile Mecp $2^{308 / Y}$ mice still failed to show a decrease in the interaction time suggests lack of recognition. These data indicate that in addition to deficits of social interaction, $M e c p 2^{308 / Y}$ mice have deficits of long-term social learning and memory in a paradigm that has been shown to be dependent on the function of the hippocampus.

\section{Mecp $2^{308 / Y}$ mice do not display abnormalities of cortical neuronal morphology or misexpression of synaptic markers} We performed Golgi staining to determine whether Mecp $2^{308}$ mutant mice have abnormalities of neuronal morphology similar to those detected in human RTT brains using this technique (Armstrong et al., 1995). Because human pathological data were obtained from the brains of symptomatic individuals, we reasoned that the analysis of older, more severely affected mice may more closely approximate the conditions found in patients. Hence, we first analyzed the cortex of Mecp $2^{308 / Y}$ mice of more than 1 year of age. By this age, mutant males display profound phenotypic abnormalities, including significant wasting, hypoactivity, and clasping. Qualitative observation of Golgi-stained cortical and subcortical sections did not reveal obvious differences of neuronal morphology between $M e c p 2^{308 / Y}$ mice and controls. Camera lucida drawings and Sholl analysis were then performed on basal and apical dendrites of layer III and V pyramidal neurons in frontal cortex. No significant differences were identified in the Sholl analysis (Fig. $2 A-D$ ). Similar results were obtained on frontal cortex of early symptomatic 6-week-old Mecp $2^{308 / Y}$ mice (data not shown). Abnormalities of synaptic composition have also been reported in RTT (Belichenko et al., 1997; Colantuoni et al., 2001), suggesting an impairment of synaptic transmission. We sought to determine whether the biochemical composition of synaptic terminals was altered in old Mecp $2^{308 / Y}$ mice. Using antibodies against several synaptic markers (supplemental Table 1, available at www.jneurosci.org as supplemental material), no differences were detected in the composition of synaptosomes and/or postsynaptic densities purified from the forebrains of wild-type and Mecp $2^{308 / Y}$ mice. Overall, these data demonstrate that despite the presence of significant behavioral abnormalities, $M e c p 2^{308 / Y}$ mice do not display changes of neuronal morphology or misexpression of synaptic markers by means of the same tech-
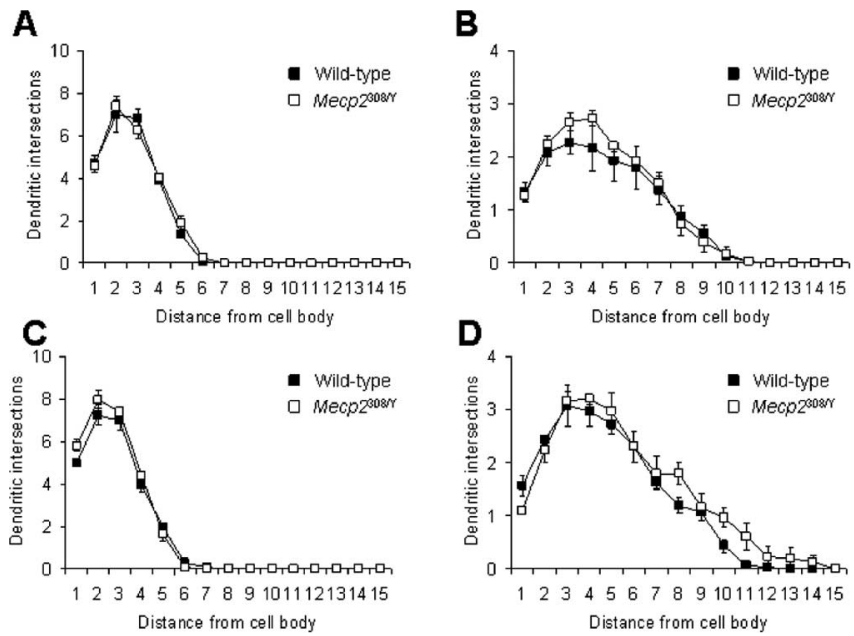

Figure 2. Neuronal dendritic arborizations are not significantly altered in $M e c p 2^{308 / Y}$ mice. $\boldsymbol{A}-\boldsymbol{D}$, Sholl analysis of basal and apical dendrites of pyramidal neurons in frontal cortex layer III and layer V. $\boldsymbol{A}, \boldsymbol{B}$, Number of basal $(\boldsymbol{A})$ and apical $(\boldsymbol{B})$ dendrites at increasing distance from the soma of pyramidal neurons in frontal cortex layer III. $\boldsymbol{C}, \boldsymbol{D}$, Number of basal $(\boldsymbol{C})$ and apical (D) dendrites at an increasing distance from the soma of pyramidal neurons in frontal cortex layer $V$. Values on the $x$-axis represent individual concentric $20 \mu \mathrm{m}$ rings centered on the cell body and at an increasing distance. Analysis of 30 neurons per cortical layer and genotype failed to reveal significant abnormalities in the morphology of neuronal processes of 12- to 15-month-old Mecp $2^{308 / Y}$ mice. Values represent mean \pm SEM.

niques used to identify reduction of dendritic arborizations and alterations of synaptic composition in human RTT samples.

Mecp $2^{308 / Y}$ mice have smaller PSDs in area CA1 of the hippocampus

To determine whether ultrastructural abnormalities are present in synapses of mutant mice, we performed transmission electron microscopy of preparations of area CA1 from 6-week-old mice (Fig. $3 A, B$ ). Wild-type and Mecp $2^{308 / Y}$ mice showed similar density of asymmetric synapse PSDs (Fig. 3C). The number of both docked synaptic vesicles and undocked vesicles (close to but not in contact with the presynaptic membrane) were also not significantly different between genotypes (Fig. 3D). Although the range of PSD length measurements was similar between genotypes (421 $\mathrm{nm}$ in wild-type vs 419 in mutant samples), analysis of the distribution of PSD length measurements revealed a reduction in the number of larger PSD $(>150 \mathrm{~nm})$ and a corresponding relative increase in the number of smaller PSDs in Mecp $2^{308 / Y}$ mice. The mean PSD length was reduced by $11.5 \%$ (Mann-Whitney $U$ test; $p<0.05$ ) in Mecp $2^{308 / Y}$ mice (Fig. $3 E$ ); median PSD values were $15 \%$ lower in mutant samples (Fig. $3 F$ ).

Mecp $2^{308 / Y}$ mice display abnormalities of basal synaptic transmission and short-term plasticity in area CA1 of the hippocampus

To determine whether synaptic dysfunction was present in mutant mice, we studied area CA1 of the hippocampus, a region implicated in the formation of several different types of memory. First, we investigated the effect of the Mecp $2^{308}$ mutation on connectivity of Schaffer-collateral synapses. Analysis of input-output curves showed that Mecp $2^{308 / Y}$ mice had a significantly greater ratio of fEPSP:fiber volley slope than control littermates, suggesting enhanced synaptic transmission (Fig. $4 A)\left(F_{(2,20)}=\right.$ $37 ; p<0.0001$; slices, $n=43 \mathrm{wt}, n=34 \mathrm{Mecp} 2^{308 / \mathrm{Y}}$; animals, $n=$ $\left.10 \mathrm{wt}, n=9 \mathrm{Mecp} 2^{308 / \mathrm{Y}}\right)$. An enhancement in synaptic transmission could be attributable to an increase in either presynaptic or postsynaptic function. PPF was impaired in Mecp $2^{308 / Y}$ mice 
A

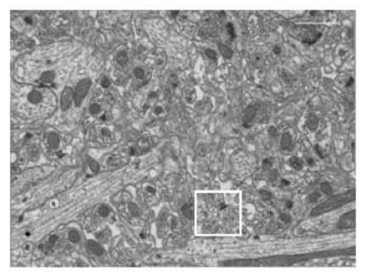

B

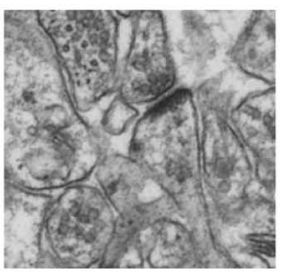

C

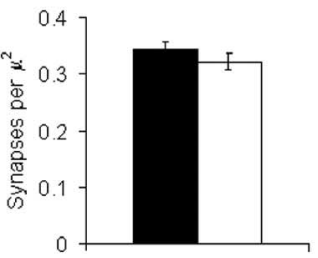

D
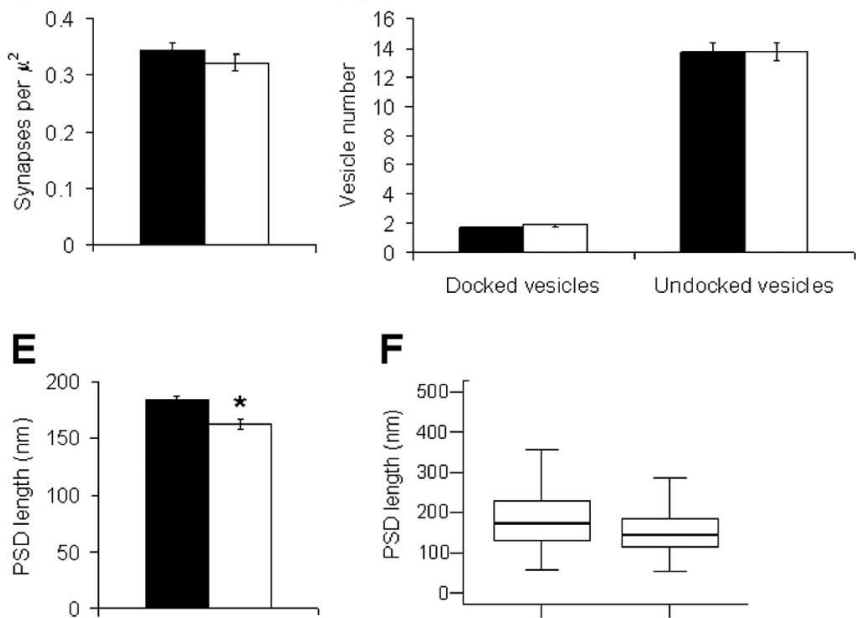

F

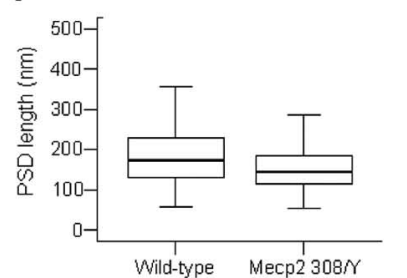

- Wild-type

口 $M e c p 2^{308 \pi}$

Figure 3. The length of PSDs at asymmetric synapses in area CA1 of the hippocampus is reduced in $M e c p 2^{308 / Y}$ mice. $A$, Micrograph of a representative region of area CA1. The inset highlights the region enlarged in $\boldsymbol{B}$. Scale bar, $1 \mu \mathrm{m}$. $\boldsymbol{B}$, Enlarged image of the inset in $\boldsymbol{A}$ showing a presynaptic terminal juxtaposed to a postsynaptic terminal. $\boldsymbol{C}$, Wild-type and Mecp $2^{308 / Y}$ mice have similar densities of PSDs in area CA1 of the hippocampus. D, The number of docked and undocked synaptic vesicles in area CA1 is not significantly different between wild-type and $M e c p 2^{308 / Y}$ mice. $\boldsymbol{E}$, The average length of PSDs is significantly reduced ( $p<$ $0.05)$ in area CA1 of Mecp $2^{308 / Y}$ mice. $\boldsymbol{F}$, Box plot of PSD length in area CA1 of wild-type and Mecp $2^{308 / Y}$ mice depicting the median and interquartile ranges. Values in $\boldsymbol{C}-\boldsymbol{E}$ represent mean \pm SEM. The asterisk in $\boldsymbol{E}$ indicates a significant genotype difference $\left({ }^{*} p<0.05\right)$. Error bars indicate SEM.

(Fig. $4 B)\left(F_{(1,76)}=10 ; p<0.005\right.$; slices, $n=43$ wt, $n=34$ Mecp $2^{308 / Y}$; animals, $\left.n=10 \mathrm{wt}, n=9 \mathrm{Mecp} 2^{308 / Y}\right)$. This modest impairment of PPF could be because of an increase in neurotransmitter release, or alternatively, a decrease in inhibitory tone in the hippocampus. However, when considered together, these findings suggest that Schaffer-collateral synaptic transmission in mutant animals is enhanced, which could account, at least in part, for the increased synaptic connectivity.

\section{Two different forms of long-term potentiation are impaired in} area CA1 of Mecp $2^{308 / Y}$ mice

The augmentation of basal synaptic transmission suggests that synapses in Mecp $2^{308 / Y}$ mice might have an enhanced ability to undergo synaptic plasticity. However, Mecp $2^{308}$ mutant mice exhibited significantly less early phase LTP (E-LTP) when induced with two $100 \mathrm{~Hz}$ tetani (Fig. $5 A)\left(F_{(1,31)}=28 ; p<0.0001\right.$; slices, $n=14 \mathrm{wt}, n=19$ Mecp $2^{308 / \mathrm{Y}}$; animals, $n=10 \mathrm{wt}, n=9$ $\left.M e c p 2^{308 / Y}\right)$. Significant deficits in synaptic potentiation were also observed when E-LTP was induced with theta-burst stimulation, a more physiologically relevant stimulus (Fig. $5 B)\left(F_{(1,27)}\right.$ $=28 ; p<0.0001$; slices, $n=15 \mathrm{wt}, n=14 \mathrm{Mecp} 2^{308 / \mathrm{Y}}$; animals, $n=10$ wt, $\left.n=9 \operatorname{Mecp} 2^{308 / Y}\right)$. The observation that two mecha-
A

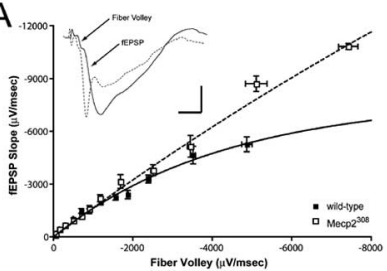

B

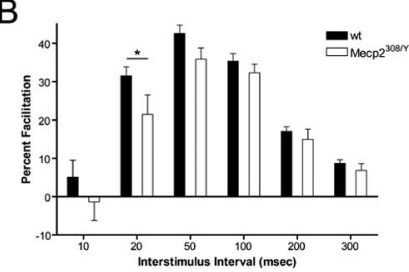

Figure 4. Synaptic transmission is enhanced in Mecp $2^{308 / Y}$ mice. Input- output relationships and paired-pulse facilitation was assessed in Mecp $2^{308 / \mathrm{Y}}$ and littermate mice at 18-22 weeks of age. $A$, Synaptic transmission as assessed by measuring the relationship of the rising slope of the fEPSP (postsynaptic depolarization) versus the rising slope of the fiber volley (presynaptic depolarization) over various stimulus intensities was significantly enhanced in Mecp $2^{308 / Y}$ mice relative to littermates. Inset, Representative traces show wt (solid line) and Mecp $2^{308 / Y}$ (dashed line) responses when maximal stimulus intensities were applied. Calibration: $1 \mathrm{mV}, 5 \mathrm{~ms}$. Note the identical slopes of the fiber volley, but the $M e c p 2^{308 / Y}$ slice exhibits a dramatically larger fEPSP slope. $\boldsymbol{B}$, Paired-pulse facilitation was significantly attenuated in Mecp $2^{308 / Y}$ mice relative to littermates, indicating neurotransmitter release was enhanced. Error bars indicate SEM.
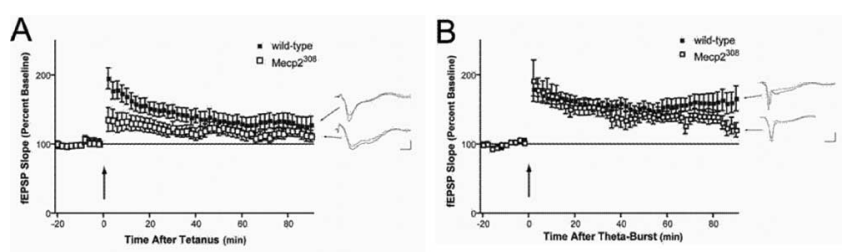

Figure 5. Long-term potentiation is impaired in area CA1 of the hippocampus of $M e c p 2^{308 / \mathrm{r}}$ mice. Two different forms of LTP were assessed in Mecp $2^{308}$ and littermate animals at 18-22 weeks of age. $\boldsymbol{A}$, LTP induced with two $100 \mathrm{~Hz}$ tetani ( 1 s, 20 s apart) was significantly impaired in Mecp $2^{308 / Y}$ mice relative to littermate controls. $B$, LTP induced with theta-burst stimulation was significantly impaired in $M e c p 2^{308 / 7}$ mice relative to littermate controls. A two-way ANOVA with repeated measures was used to analyze both data sets throughout the duration of the whole experiment. Representative traces are shown to the right of summary data. Calibration: $2 \mathrm{mV}, 5 \mathrm{~ms}$. Error bars indicate SEM.

nistically distinct forms of E-LTP (Selcher et al., 2003) are impaired in mice expressing a truncated Mecp2 protein suggests that Mecp 2 plays an important role in the induction of synaptic plasticity in general.

\section{Long-term depression is impaired in area CA1 of early} symptomatic Mecp $2^{308 / Y}$ mice

To further explore the hypothesis that Mecp2 is important for induction of synaptic plasticity in general, we investigated the induction of group I mGluR-dependent LTD at Schaffercollateral synapses of Mecp $2^{308 / Y}$ and wt mice. Because LTD is difficult to experimentally induce in vitro from tissue derived from older animals, we studied 4- to 6-week-old mice. At this age, Mecp $2^{308 / Y}$ mice are only very mildly symptomatic, inconsistently showing forelimb stereotypies but no other neurologic symptom. As in older mice, synaptic connectivity was enhanced in the hippocampus of 4- to 6-week-old Mecp $2^{308 / Y}$ mice, indicating that synaptic defects are present even at this early age (Fig. $6 A)\left(F_{(2,14)}=41 ; p<0.0001\right.$; slices, $n=18 \mathrm{wt}, n=20 \mathrm{Mecp}^{308 / \mathrm{Y}}$; animals, $\left.n=6 \mathrm{wt}, n=6 \mathrm{Mecp} 2^{308 / Y}\right)$. Subsequently, we investigated two forms of LTD. The first form involved exposing slices to the group I mGluR agonist DHPG $(50 \mu \mathrm{M})$ for $10 \mathrm{~min}$. Group I mGluR-LTD relies entirely on postsynaptic mechanisms for its induction and expression in mice 4 weeks of age and older (Nosyreva and Huber, 2005). Therefore, treatment of slices with DHPG directly engages postsynaptic group I mGluRs and does not depend on presynaptic function for its induction. DHPGinduced LTD was similar in wild-type and $M e c p 2^{308 / Y}$ mice, in- 

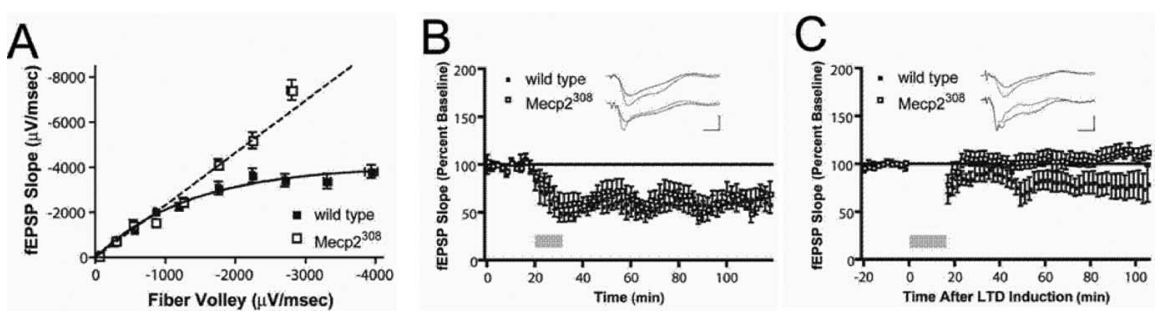

Figure 6. Long-term depression is impaired in area CA1 of the hippocampus of Mecp $2^{308 / \mathrm{V}}$ mice. Two different forms of LTD were assessed in $M e c p 2^{308 / \mathrm{N}}$ mice and littermates at 4-7 weeks of age. $\boldsymbol{A}$, Input-output was significantly enhanced in Mecp $2^{308 / Y}$ mice relative to littermate controls, indicating that the enhancement in basal synaptic connectivity was present at an early age. $B$, LTD induced by the group I mGluR agonist DHPG $(50 \mu \mathrm{m})$ was unaffected by the $M e c p 2^{308}$ mutation. $C$, LTD induced by 900 paired stimuli $(50$ ms interstimulus interval, $1 \mathrm{~Hz})$ in the presence of AP-5 $(50 \mu \mathrm{M})$ was significantly impaired in Mecp $2^{308 / \mathrm{Y}}$ mice relative to littermate controls. Representative traces are shown above summary data. Calibration: $1 \mathrm{mV}, 5 \mathrm{~ms}$. Error bars indicate SEM.
A
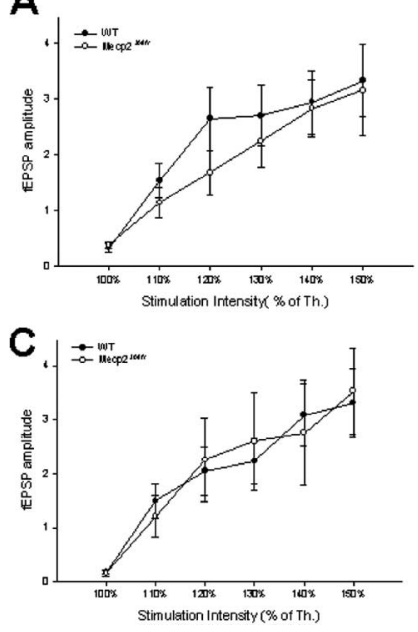

B
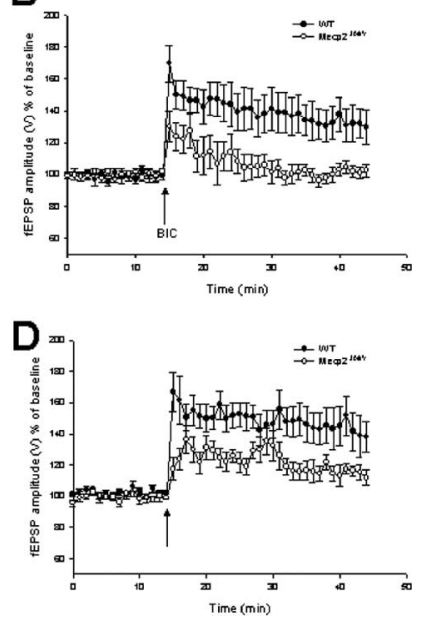

Figure 7. Long-term potentiation is impaired in primary motor and sensory cortex of Mecp $2^{308 / Y}$ mice. $A$, Cumulative plot of the input-output curves (field potential recruitment recorded in layer II/III of M1 motor cortex) shows normal basal synaptic transmission in Mecp $2^{308 / Y}$ mice compared with control littermates $(p>0.05)$. $\boldsymbol{B}$, M1-LTP is impaired in Mecp $2^{308 / Y}$ mice compared with control littermates $(p=0.01)$. C, Cumulative plot of the input- output curves (field potential recruitment recorded in layer II/III of S1 sensory cortex) shows normal basal synaptic transmission in $M e c p 2^{308 / v}$ mice compared with control littermates $(p>0.05) \cdot D, S 1-L T P$ is impaired in Mecp $2^{308 / Y}$ mice compared with control littermates $(p=0.02)$. Values represent mean \pm SEM.

dicating that mutation of Mecp2 does not alter group I mGluRinduced signaling, nor does it prevent Schaffer-collateral synapses from exhibiting LTD or plastic changes in general (Fig. 6B) $\left(F_{(1,17)}=2 ; p<0.1\right.$; slices, $n=10 \mathrm{wt}, n=9 \mathrm{Mecp} 2^{308 / \mathrm{Y}}$; animals, $n=3$ wt, $\left.n=3 \mathrm{Mecp} 2^{308 / Y}\right)$. Induction of group I mGluR-LTD can also be accomplished using a paired-pulse lowfrequency stimulation (PP-LFS) paradigm (Huber et al., 2000). PP-LFS-LTD does not require the presynaptic terminal for expression of plasticity; however, PP-LFS-LTD is absolutely dependent on the presynaptic terminal for its induction. Slices from animals that expressed the truncated form of Mecp2 exhibited no PP-LFS-LTD (Fig. $6 C)\left(F_{(1,17)}=165 ; p<0.0001\right.$; slices, $n=8 \mathrm{wt}$, $n=11 M e c p 2^{308 / Y}$; animals, $\left.n=4 \mathrm{wt}, n=4 M e c p 2^{308 / \mathrm{Y}}\right)$. Therefore, truncation of Mecp2 impairs the expression of group I mGluR-LTD when induced using PP-LFS, suggesting that alterations in the presynaptic terminal have rendered Schaffercollateral synapses unable to induce group I mGluR-LTD, although they are fully capable of expressing group I mGluR-LTD. Together with the results obtained investigating LTP, our results suggest that truncation of Mecp2 causes significant defects in the induction of various forms of synaptic plasticity in general. Furthermore, these changes can be detected in mutant mice before the development of severe neurologic dysfunction.

Synaptic connections at layer II/III of primary motor and sensory cortex show reduced long-term potentiation in $\mathrm{Mecp} 2^{308 / Y}$ mice

There is evidence that synaptic plasticity occurs both at connections of layer II-III of primary motor cortex (M1) (RioultPedotti et al., 1998, 2000) and at layer II-III of primary sensory cortex (S1) (Hardingham et al., 2003). To determine whether functional synaptic dysfunction extended beyond the hippocampus, we investigated synaptic transmission and plasticity in the frontal cortex of wild-type and Mecp $2^{308 / Y}$ mice of 35-40 weeks of age. The study of fEPSPs at layers II/III of primary motor cortex (M1) did not show significant changes of basal synaptic transmission in $M e c p 2^{308 / Y}$ mice compared with control littermates. fEPSP at $150 \%$ of threshold stimulation was $3.1 \pm 0.8 \%$ in mutant mice compared with $3.3 \pm 0.6 \%$ in wildtype $\left(F_{(1,12)}=0.35 ; p=0.5\right)$ (Fig. $\left.7 A\right)$. Similar results were obtained with the study of basal synaptic transmission in primary sensory cortex (S1). fEPSP slope at $150 \%$ of the threshold stimulation was $3.5 \pm 0.8 \%$ in $M e c p 2^{308 / Y}$ mice compared with $3.3 \pm$ $0.6 \%$ in wild-type $\left(F_{(1,12)}=0.03 ; p=0.9\right)$ (Fig. $\left.7 C\right)$. Brain slices from $M e c p 2^{308 / Y}$ and wild-type mice were next tested for their ability to undergo plastic changes in response to high-frequency stimulation. LTP was induced in cortical slices from Mecp $2^{308 / Y}$ mice and their littermate controls. At $30 \mathrm{~min}$ after LTP induction in $\mathrm{M} 1$ area, we observed a $129.6 \pm 10.3 \%$ increase in potentiation in wild-type mice ( $n=7$ slices from five animals), whereas Mecp $2^{308 / Y}$ littermates only showed a $102.8 \pm 3.8 \%$ increase $(n=$ 7 slices from five animals; $\left.F_{(1,12)}=7.7 ; p=0.01\right)$ (Fig. $\left.7 B\right)$. LTP was also impaired in Mecp $2^{308 / Y}$ mice in the $S 1$ region. The amount of potentiation at $30 \mathrm{~min}$ after tetanus was $137.7 \pm 0.6 \%$ of baseline in wild-type ( $n=7$ slices from five animals) and $111.0 \pm 7.0 \%$ in Mecp $2^{308 / Y}$ mice ( $n=7$ slices from five animals) $\left(F_{(1,12)}=6.4 ; p=0.02\right)$ (Fig. $\left.7 D\right)$. These data suggest that symptomatic Mecp $2^{308 / Y}$ mice have alterations of synaptic plasticity in at least two areas of the neocortex.

\section{Discussion}

We have shown that Mecp $2^{308 / Y}$ mice display deficits of learning and memory in three behavioral paradigms dependent on the function of the hippocampus and have abnormalities of synaptic structure and function in area CA1 of the hippocampus. Using the hidden platform version of the Morris water maze, contextual fear conditioning, and long-term social memory (Kogan et al., 2000), adult $M e c p 2^{308 / Y}$ mice demonstrated significant learning and memory deficits. Although memory per se has not been demonstrated to be impaired in RTT and related disorders, cognitive abnormalities are present in individuals with $M E C P 2$ mutations, supporting the notion that results obtained in Mecp $2^{308 / Y}$ mice may represent a correlate of the mental retardation of RTT patients. Previous experiments performed in Mecp $2^{308 / Y}$ mice of highly mixed 129/SvEv $\times$ C57BL/6 genetic background did not reveal learning abnormalities using the Morris water maze and fear conditioning tests (Shahbazian et al., 2002). Two factors may account for this discrepancy: differences in genetic background 
and the intensity of the training paradigm. We used a pure inbred strain $(129 / \mathrm{SvEv})$ that, in contrast to other genetic backgrounds such as $129 / \mathrm{SvJ}$, is capable of complex learning similar to C57BL/6J mice (Owen et al., 1997). Use of a pure strain avoids the confounding and unpredictable effects of variable contributions from two highly mixed genetic backgrounds. Compared with Shahbazian et al. (2002), we also used less intense training conditions in both Morris water maze and contextual fear conditioning. In this respect, it is interesting to note that we found no significant differences between $M e c p 2^{308 / Y}$ and wild-type littermates using a fear conditioning training protocol similar to that used by Shahbazian et al. (2002) (Moretti and Zoghbi, unpublished data). This suggests that more intense training conditions can overcome the learning and memory deficits of mutant mice.

In contrast with results of human pathological studies (Armstrong et al., 1995; Belichenko et al., 1997), the brains of severely affected $M e c p 2^{308 / Y}$ mice did not demonstrate reduced dendritic arborizations in pyramidal neurons of layer III and V of frontal cortex or abnormal expression of synaptic markers in purified forebrain synaptic terminals. Furthermore, analysis of synaptic density in area CA1 of the hippocampus did not reveal a reduction of synapses/dendritic spine density. Although the same methodology used in human RTT studies was also used in these mouse experiments, important differences still remain. First and foremost, the short life span of the mouse may not allow full recapitulation of pathologic events resulting from $\mathrm{MeCP} 2$ dysfunction. If this hypothesis is correct, it is conceivable that electrophysiological and subtle ultrastructural abnormalities precede in time the development of more profound neuronal dysfunction associated with morphological and biochemical derangements. Second, data obtained from postmortem human samples may be influenced by the small genetically heterogeneous sample size and by associated comorbidities, factors that were excluded from our studies. Despite these differences, it is interesting to note a convergence between our studies and human data pointing to the synapse as a critical site of pathology in RTT.

Results of our electrophysiological and ultrastructural studies demonstrate that learning and memory deficits in vivo are associated with synaptic dysfunction. Enhancement of synaptic transmission and deficits of short-term synaptic plasticity and LTP were detected at Schaffer-collateral synapses of symptomatic $M e c p 2^{308 / Y}$ mice. Increased synaptic transmission and decreased LTD were found in early symptomatic mutant mice. Overall, these data suggest that synaptic dysfunction is an early event in the pathogenesis of RTT, preceding the development of significant neurological manifestations. Although these electrophysiology data do not allow a precise dissection of the relative contribution of presynaptic and postsynaptic effects, the results suggest that presynaptic dysfunction may play a role in the deficits observed at Schaffer-collateral synapses. For instance, paired-pulse facilitation, a measure of presynaptic neurotransmitter release, was impaired in Mecp $2^{308 / Y}$ mice. Moreover, LTD was impaired in mutant mice using a paired-pulse stimulation paradigm (which requires intact presynaptic function for its induction). However, LTD was not impaired when induced using bath application of DHPG, a postsynaptic group I mGluR agonist that may not depend on presynaptic function. Deficits of synaptic plasticity were also observed at layer II/III synapses of motor and sensory cortex, indicating that abnormalities of synaptic function extend beyond the hippocampus and involve additional brain regions, including the neocortex. The impairment of synapses in the neocortex of Mecp $2^{308 / Y}$ mice is particularly interesting given the clinical evidence of involvement of frontal, motor, and tem- poral brain regions in RTT (Armstrong et al., 1995; Subramaniam et al., 1997). In contrast with data obtained in area CA1 of the hippocampus, synaptic connectivity did not appear to be altered in the motor and sensory cortex of Mecp $2^{308 / Y}$ mice. This finding suggests that separate regions of the brain may respond differently to $\mathrm{MeCP} 2$ dysfunction, a hypothesis supported by human clinical data indicating region-specific abnormalities in the brain of RTT patients.

Interestingly, the electron microscopy results revealed a reduction of the length of PSD at CA1 excitatory synapses in the presence of unchanged density of synapses and number of docked and undocked vesicles. These data indicate the presence of a mismatch between the number of vesicles and the average size of the PSD in early symptomatic Mecp $2^{308 / Y}$ mice, with a higher ratio in the mutants. A quantitative three-dimensional ultrastructural analysis of hippocampal excitatory synapses demonstrated a close correlation between active zone and PSD size (Schikorski and Stevens, 1997). Because the active zone often lacks clearly definable boundaries in cross section, it is generally defined ultrastructurally as the presynaptic membrane in direct juxtaposition to the PSD. Thus, our findings suggest that asymmetric synapses in area CA1 of $M e c p 2^{308 / Y}$ mice either have a higher density of docked vesicles at the active zone or smaller PSDs in the absence of compensatory changes in the size of active zones. Increased BDNF expression has been identified in neuronal cultures prepared from Mecp2 null mice (Chen et al., 2003; Martinowich et al., 2003). However, quantitative real-time PCR analysis of $B D N F$ expression in the hippocampus of wild-type and $M e c p 2^{308 / Y}$ mice did not reveal significant abnormalities (Moretti and Zoghbi, unpublished result). Although it remains possible that heterogeneous single-cell $B D N F$ expression changes occur in Mecp $2^{308 / Y}$ mice, this and other results suggest that additional factors may play a role in our electrophysiology and ultrastructural results. For instance, exogenous application of BDNF to normal rat hippocampal slices increases the number of docked vesicles at CA1 excitatory synapses (Tyler and PozzoMiller, 2001), a result contrary to our observation in vivo. Future studies will explore the molecular mechanisms associated with synaptic dysfunction in the hippocampus of Mecp $2^{308 / Y}$ mice.

Loss-of-function $M e c p 2^{308 / Y}$ mice and transgenic mice with mild overexpression of MeCP2 (MeCP2 ${ }^{\mathrm{Tg}}$ ) (Collins et al., 2004) appear to display opposite electrophysiological phenotypes at Schaffer-collateral synapses, suggesting that MeCP2 plays an important role in the regulation of synaptic function. For instance, $M e c p 2^{308 / Y}$ mutants show decreased PPF and LTP, whereas $\mathrm{MeCP} 2^{\mathrm{Tg}}$ showed enhancement of synaptic plasticity by these measures. These findings suggest that $\mathrm{MeCP} 2$ may directly control molecular mechanisms (or target genes) responsible for the regulation of synaptic plasticity. For instance, loss of MeCP2 function may cause overexpression or underexpression of a target gene(s) resulting in synaptic dysfunction, whereas its overexpression causes the opposite effect on expression of the same target gene(s) strengthening synaptic function. Understanding the molecular events that follow MeCP2 dysregulation and their impact on synaptic function are key questions in RTT research. Molecular profiling experiments comparing gene expression abnormalities in both mouse models may provide an insight into the molecular targets of MeCP2 and suggest molecular links between methylation-dependent regulation of gene expression and synaptic function. Such studies may have clinical relevance that extends beyond RTT. MECP2 gene duplications have been identified in a preserved speech variant RTT girl and several boys with severe mental retardation and features of RTT (Ariani et al., 2004; 
Meins et al., 2005; Van Esch et al., 2005), suggesting that increased dosage of MeCP2 may be detrimental to cognition. Furthermore, MECP2 expression abnormalities have been identified in the brain of children affected with a range of neurodevelopmental disorders including autism, Prader-Willi, and Angelman syndrome (Samaco et al., 2004).

In summary, these data provide evidence that mutation of $M E C P 2$ causes synaptic dysfunction and learning and memory deficits in the mouse. The elucidation of the cascade of molecular events triggered by MeCP2 dysfunction will further our understanding of RTT and the role of methylation-dependent transcriptional silencing in neuronal function.

\section{References}

Amir RE, Van den Veyver IB, Wan M, Tran CQ, Francke U, Zoghbi HY (1999) Rett syndrome is caused by mutations in X-linked MECP2, encoding methyl-CpG-binding protein 2. Nat Genet 23:185-188.

Amir RE, Van den Veyver IB, Schultz R, Malicki DM, Tran CQ, Dahle EJ, Philippi A, Timar L, Percy AK, Motil KJ, Lichtarge O, Smith EO, Glaze DG, Zoghbi HY (2000) Influence of mutation type and X chromosome inactivation on Rett syndrome phenotypes. Ann Neurol 47:670-679.

Ariani F, Mari F, Pescucci C, Longo I, Bruttini M, Meloni I, Hayek G, Rocchi R, Zappella M, Renieri A (2004) Real-time quantitative PCR as a routine method for screening large rearrangements in Rett syndrome: report of one case of MECP2 deletion and one case of MECP2 duplication. Hum Mutat 24:172-177.

Armstrong D, Dunn JK, Antalffy B, Trivedi R (1995) Selective dendritic alterations in the cortex of Rett syndrome. J Neuropathol Exp Neurol 54:195-201.

Belichenko PV, Dahlstrom A (1995) Studies on the 3-dimensional architecture of dendritic spines and varicosities in human cortex by confocal laser scanning microscopy and Lucifer yellow microinjections. J Neurosci Methods 57:55-61.

Belichenko PV, Hagberg B, Dahlstrom A (1997) Morphological study of neocortical areas in Rett syndrome. Acta Neuropathol (Berl) 93:50-61.

Beyer KS, Blasi F, Bacchelli E, Klauck SM, Maestrini E, Poustka A (2002) Mutation analysis of the coding sequence of the MECP2 gene in infantile autism. Hum Genet 111:305-309.

Carney RM, Wolpert CM, Ravan SA, Shahbazian M, Ashley-Koch A, Cuccaro ML, Vance JM, Pericak-Vance MA (2003) Identification of MeCP2 mutations in a series of females with autistic disorder. Pediatr Neurol 28:205-211.

Chen WG, Chang Q, Lin Y, Meissner A, West AE, Griffith EC, Jaenisch R, Greenberg ME (2003) Derepression of BDNF transcription involves calcium-dependent phosphorylation of MeCP2. Science 302:885-889.

Colantuoni C, Jeon OH, Hyder K, Chenchik A, Khimani AH, Narayanan V, Hoffman EP, Kaufmann WE, Naidu S, Pevsner J (2001) Gene expression profiling in postmortem Rett syndrome brain: differential gene expression and patient classification. Neurobiol Dis 8:847-865.

Collins AL, Levenson JM, Vilaythong AP, Richman R, Armstrong DL, Noebels JL, Sweatt DJ, Zoghbi HY (2004) Mild overexpression of $\mathrm{MeCP} 2$ causes a progressive neurological disorder in mice. Hum Mol Genet 13:2679-2689.

Hagberg B, Aicardi J, Dias K, Ramos O (1983) A progressive syndrome of autism, dementia, ataxia, and loss of purposeful hand use in girls: Rett's syndrome: report of 35 cases. Ann Neurol 14:471-479.

Hardingham N, Glazewski S, Pakhotin P, Mizuno K, Chapman PF, Giese KP, Fox K (2003) Neocortical long-term potentiation and experiencedependent synaptic plasticity require alpha-calcium/calmodulindependent protein kinase II autophosphorylation. J Neurosci 23:4428-4436.

Huber KM, Kayser MS, Bear MF (2000) Role for rapid dendritic protein synthesis in hippocampal mGluR-dependent long-term depression. Science 288:1254-1257.

Huber KM, Roder JC, Bear MF (2001) Chemical induction of mGluR5- and protein synthesis-dependent long-term depression in hippocampal area CA1. J Neurophysiol 86:321-325.

Kogan JH, Frankland PW, Silva AJ (2000) Long-term memory underlying hippocampus-dependent social recognition in mice. Hippocampus 10:47-56.

Lam CW, Yeung WL, Ko CH, Poon PM, Tong SF, Chan KY, Lo IF, Chan LY, Hui J, Wong V, Pang CP, Lo YM, Fok TF (2000) Spectrum of mutations in the MECP2 gene in patients with infantile autism and Rett syndrome. J Med Genet 37:E41.

Martinowich K, Hattori D, Wu H, Fouse S, He F, Hu Y, Fan G, Sun YE (2003) DNA methylation-related chromatin remodeling in activity-dependent BDNF gene regualtion. Science 302:890-893.

Meins M, Lehmann J, Gerresheim F, Herchenbach J, Hagedorn M, Hameister K, Epplen JT (2005) Submicroscopic duplication in Xq28 causes increased expression of the MECP2 gene in a boy with severe mental retardation and features of Rett syndrome. J Med Genet 42:e12.

Moretti P, Bouwknecht JA, Teague R, Paylor R, Zoghbi HY (2005) Abnormalities of social interactions and home-cage behavior in a mouse model of Rett syndrome. Hum Mol Genet 14:205-220.

Nosyreva ED, Huber KM (2005) Developmental switch in synaptic mechanisms of hippocampal metabotropic glutamate receptor-dependent longterm depression. J Neurosci 25:2992-3001.

Owen EH, Logue SF, Rasmussen DL, Wehner JM (1997) Assessment of learning by the Morris water task and fear conditioning in inbred mouse strains and F1 hybrids: implications of genetic background for single gene mutations and quantitative trait loci analyses. Neuroscience 80:1087-1099.

Percy AK (2002) Rett syndrome. Current status and new vistas. Neurol Clin 20:1125-1141.

Rioult-Pedotti MS, Friedman D, Hess G, Donoghue JP (1998) Strengthening of horizontal cortical connections following skill learning. Nat Neurosci 1:230-234.

Rioult-Pedotti MS, Friedman D, Donoghue JP (2000) Learning-induced LTP in neocortex. Science 290:533-536.

Samaco RC, Nagarajan RP, Braunschweig D, LaSalle JM (2004) Multiple pathways regulate $\mathrm{MeCP} 2$ expression in normal brain development and exhibit defects in autism-spectrum disorders. Hum Mol Genet 13:629-639.

Schanen C, Francke U (1998) A severely affected male born into a Rett syndrome kindred supports X-linked inheritance and allows extension of the exclusion map. Am J Hum Genet 63:267-269.

Schikorski T, Stevens CF (1997) Quantitative ultrastructural analysis of hippocampal excitatory synapses. J Neurosci 17:5858-5867.

Selcher JC, Weeber EJ, Christian J, Nekrasova T, Landreth GE, Sweatt JD (2003) A role for ERK MAP kinase in physiologic temporal integration in hippocampal area CA1. Learn Mem 10:26-39.

Shahbazian M, Young J, Yuva-Paylor L, Spencer C, Antalffy B, Noebels J, Armstrong D, Paylor R, Zoghbi H (2002) Mice with truncated MeCP2 recapitulate many Rett syndrome features and display hyperacetylation of histone H3. Neuron 35:243-254.

Subramaniam B, Naidu S, Reiss AL (1997) Neuroanatomy in Rett syndrome: cerebral cortex and posterior fossa. Neurology 48:399-407.

Tyler WJ, Pozzo-Miller LD (2001) BDNF enhances quantal neurotransmitter release and increases the number of docked vesicles at the active zones of hippocampal excitatory synapses. J Neurosci 21:4249-4258.

Van Esch H, Bauters M, Ignatius J, Jansen M, Raynaud M, Hollanders K, Lugtenberg D, Bienvenu T, Jensen LR, Gecz J, Moraine C, Marynen P, Fryns JP, Froyen G (2005) Duplication of the MECP2 region is a frequent cause of severe mental retardation and progressive neurological symptoms in males. Am J Hum Genet 77:442-453.

Wan M, Lee SS, Zhang X, Houwink-Manville I, Song HR, Amir RE, Budden S, Naidu S, Pereira JL, Lo IF, Zoghbi HY, Schanen NC, Francke U (1999) Rett syndrome and beyond: recurrent spontaneous and familial MECP2 mutations at CpG hotspots. Am J Hum Genet 65:1520-1529.

Young JI, Zoghbi HY (2004) X-chromosome inactivation patterns are unbalanced and affect the phenotypic outcome in a mouse model of Rett syndrome. Am J Hum Genet 74:511-520. 